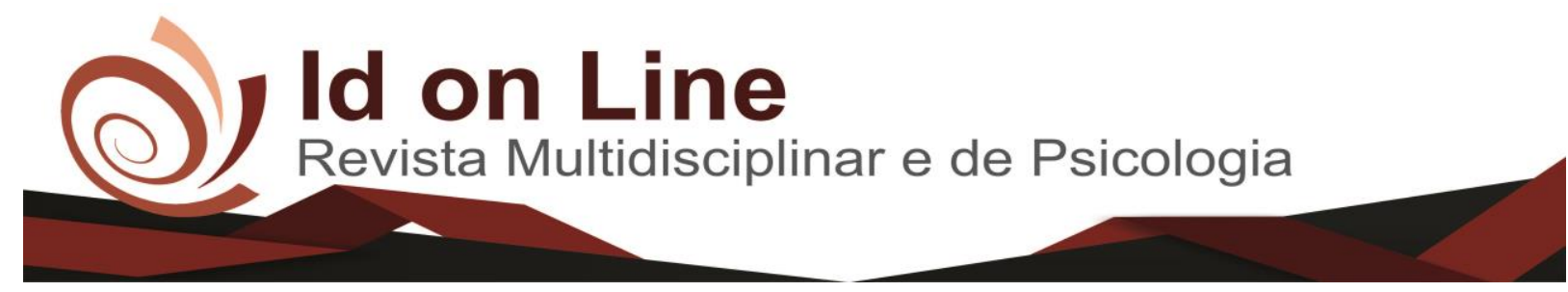

Comment

\title{
A Contribuição da Dança na Pré-Escola
}

Paula Stephane de Souza Lima ${ }^{1}$

Resumo: A dança é considerada uma manifestação cultural do movimento corporal e quando associamos ao âmbito escolar, é capaz de promover a transmissão de sentimentos, emoções e capacidades criativas e motoras da criança. Diante disso, o presente artigo teve como objetivo apresentar a importância da dança na pré-escola. Este estudo foi conduzido com a base de dados entre os meses de setembro a outubro de 2017. As pesquisas foram investigadas a partir de pesquisa bibliográfica disponibilizadas em bases de dados eletrônicos como scientific electronic library online (SCIELO), Google Scholar e periódicos da CAPES com QUALIS A, B e C, bem como as publicações listadas no site de Programas de graduação e Pós-graduação em pedagogia e em outras organizações atuantes no universo da educação. Após as análises da literatura, foi observado que a dança é capaz de promover o desenvolvimento corporal das crianças, melhorar a capacidade cognitiva e expandir sua habilidade intelectual. Dessa forma, é fundamental que os alunos da pré-escola, bem como nas demais modalidades de ensino, tenham a dança como ferramenta no universo pedagógico capaz de promover a educação e melhoria da qualidade de vida dos alunos.

Palavras-chave: aprendizagem; dança; desenvolvimento infantil

\section{The Contribution of Dance to Pre-School}

\begin{abstract}
Dance is considered a cultural manifestation of bodily movement and when associated with the school environment, it is capable of promoting the transmission of the child's feelings, emotions and creative and motor skills. This on, the present article aims to present the importance of dance in preschool. This study was conducted with the database between the months of september to october 2017. The researches were investigated from bibliographic research available in electronic databases such as scientific electronic library online (SCIELO), Google Scholar and CAPES journals with QUALIS A, B and C, as well as the publications listed on the Graduation Programs website Post-graduation in pedagogy and other organizations active in the education universe. After the analysis of the literature, it was observed that dance is capable of promoting children's body development, improving cognitive ability and expanding their intellectual ability. In this way, it is fundamental that the students of the preschool, as well as in the other modalities of teaching, have the dance as a tool in the pedagogical universe capable of promoting the education and improvement of the quality of life of the students.
\end{abstract}

Keywords: learning; dance; child development

\section{Introdução}

As atividades que utilizam o movimento têm a função de integrar, propor possibilidades de encontro consigo, com o mundo e com o conhecimento e dentre eles, destaca-se a dança. A

\footnotetext{
${ }^{1}$ Graduanda do curso de Licenciatura em Pedagogia, Faculdade de Ciências Humanas do Sertão Central - Fachusc, E-mail: paula_souza_lima@hotmail.com 
dança é caracterizada como uma das mais antigas formas de expressão corporal e artística de homem (OLIVEIRA, 2011).

É durante a infância, a criança tem a necessidade de se movimentar de forma que venham a estimular a habilidade motora e a curiosidade de cada movimento, seja subindo, descendo, agachando ou pulando.

As habilidades motoras das crianças são capazes de expandir seu ser, ressaltando a importância do movimento para o desenvolvimento da criança, aspecto defendido por Nani (1995) e frisado por Fux (1983). Educar a criança de forma divertida está entre um dos papeis do professor e uma das maneiras dele buscar isso, está baseada na aplicação da dança como atividade edicativa.

A dança possui uma importante ligação com a educação, visto que no universo pedagógico ela auxilia o desenvolvimento do aluno, facilitando sua aprendizagem e resultando na construção do conhecimento, contribuindo para o aprimoramento das habilidades básicas, dos padrões fundamentais do movimento, no desenvolvimento das potencialidades complementa as atividades pedagógicas (LAUAR; MATTOS, 2014).

Assim, a dança como carácter educativo contribui no desenvolvimento de quatorze diferentes aspectos que são: aprendizagem, compromisso, cidadania, responsabilidade, interesse, senso critico, criatividade, envolvimento, sociabilização, comunicação, respeito, livre expressão e cooperação, trabalhando desta maneira a ação - sensação e reflexão dos alunos (SCARPATO, 2001).

Assim, justifica-se a realização desta pesquisa em razão da autora trabalhar diretamente com a temática em questão e perceber, através das práticas pedagógicas realizadas com alunos da educação infantil, as contribuições que a dança propõe junto ao ambiente lúdico das crianças.

Além disso, essa obra bsuca proproconar como leitura para toda a comunidade acadêmica que tenham ligações e/ou afinidade com essa temática. Dessa forma, o presente artigo teve como objetivo apresentar a importância da dança na pré-escola.

\section{Metodologia}

Este estudo foi conduzido com a base de dados entre os meses de agosto a setembro de 2017. As pesquisas foram investigadas a partir de pesquisa bibliográfica disponibilizadas em bases de dados eletrônicos como scientific electronic library online (SCIELO), Google Scholar 
e periódicos da CAPES com QUALIS A, B e C, assim como as publicações listadas no site no site de Programas de graduação e Pós-graduação em pedagogia e em outras organizações atuantes no universo da educação.

Para a busca dos trabalhos, foram utilizados como palavras chaves os descritores: educação infantil, pré-escolar, dança na pré-escola e metodologias de ensino da dança na préescola.

Dessa forma, para uma melhor compreensão da temática aqui abordada, a revisão bibliográfica concentrou-se em trabalhos nacionais e internacionais para melhorar e enriquecer a qualidade da pesquisa bibliográfica aplicada ao tema. Dentre os autores que foram fundamentais para a revisão literária dessa obra, estão: Trevisan, Fux, Scarpato, Damásio, Calfa e outros.

\section{A dança e o desenvolvimento humano}

A dança é a arte do movimento humano, ela é plástico-rítmica, abstrata e expressiva, uma das artes mais antigas conhecidas, aparecendo desde os primórdios das civilizações como uma manifestação natural, muitas vezes como forma de ritual GARCIA; GLITZ, (2009, p.4).

Segundo Marbá et al. (2016), a dança tem o poder de promover o desenvolvimento integral do ser humano. Dessa forma, o nosso corpo passa a ser a expressão de nosso gênero, etnia, faixa etária, crença espiritual, classe social que ao dançar traz a ideia de que "eu sou um corpo" e não de que "eu tenho um corpo" (MARQUES, 2010).

Essa lógica de pensamento desses autores, trás uma reflexão sobre o dinamismo que a dança é capaz de promover sobre as nossas atitudes, como ser humano em meio aos olhares da sociedade.

Para Wallon (1975), o desenvolvimento do ser humano é como uma construção progressiva em que se sucedem fases com predominância alternadamente afetiva e cognitiva. A dança, nesta visão, é capaz de aproveitar as características comuns do desenvolvimento humano, transformando-as em atividades reconhecidas como a referida arte.

Essas expressões começam na infância, onde a criança normalmente transmite as curiosidades em aprender e entender um algo novo. Em relato de Fux (1983, p. 67) sobre a música no desenvolvimento humano, descreve que: 
Quando somos crianças necessitamos mover-nos porque movendo-nos expressamos nossa vontade de rir, de chorar ou de brincar. À medida que crescemos, nosso corpo, pelos tabus de uma civilização que corrompe nossa necessidade de expressão, perde cada vez mais o desejo de mobilização. É aí que devemos recorrer, já adultos, a experiências para "melhorar o físico" em academias de ginástica, onde sem pensálo, não só melhoramos como descartamos a energia acumulada por tantos "não" impostos. Mas que maravilha seria se soubéssemos comunicar-nos com o nosso corpo, estimulados pelo desejo de expressar-nos com a música ou sem ela, mas fazendo do corpo um instrumento de comunicação entre o que queremos fazer, entre o que podemos fazer e entre o que vamos descarregando para podermos nos expressar (FUX, 1983, p. 67).

Além dessa transmissão de expressões por meio da dança, a criança de forma instatânea, promove outros benefícios para o seu desenvolvimento, como trabalhar fortalecendo a musculatura, estimulando a coordenação motora, maior flexibilidade, consciência corporal, noções de espaço, bem como a melhoraria na sua integração social.

A dança também ajuda a libertar as tensões internas. Além disso, ela melhora as habilidades motoras, de memória e de equilíbrio, mas contribui, sobretudo, para a construção de auto-confiança do seu filho.

\section{A Importância da Dança na Educação}

No contexto geral são indiscutíveis os benefícios da dança como uma atividade educativa. As qualidades de movimento implícito nas diversas formas de expressão humana e dessa forma o aluno poderar ser educadas (MARQUES, 1999).

Uma criança que na pré-escola teve a oportunidade de participar de aulas de dança, certamente, terá mais facilidade para ser alfabetizada. (TREVISAN, 2006). Essa afirmativa reforça cada vez mais a importância da dança no contexto educacional e em especial na educação infantil.

Silva (2009) cita que a dança na escola pode desenvolver na criança a compreensão de capacidade de movimento mediante um maior entendimento de como funciona, assim poderá usá-lo como maior inteligência, autonomia, responsabilidade e sensibilidade. Isso provoca a melhoria da qualidade de vida do aluno, bem como o seu potencial em expressar alguma habilidade corporal.

Desta forma Souza et al (2010) relatam que aplicação da dança como processo educacional, prioriza o desenvolvimento nos aspectos físico, mental e sócio afetivo, fazendo 
com que a criança amplie seu acervo motor, expressividade e criatividade adquirindo domínio sobre seus movimentos corporais. Isso corrobora com a percerpção de que a dança tem um carácter educativo e ao mesmo tempo saudável para criança.

Oliveira (2001) ainda complementa que por meio das atividades de dança, a criança evolui quanto ao seu domínio corporal, desenvolve e aprimora suas possibilidades de movimentação, descobre novos espaços, supera suas limitações para enfrentar novos desafios. Além disso, a dança pode e deve ser integrada com outras disciplinas para que seja possível uma contribuição para o processo pedagógico (SCARPATO, 2001)

O ensino da dança na escola não deve fixar-se como formador de futuros bailarinos, mas relacionar-se imediatamente com a vida das crianças, como parte integrante da educação delas (STRAZZACAPPA; MORANDI, 2006). Dessa forma a contribuição da dança como ferramenta de ensino, torna-se fundamental nas escolas.

Porém, de acordo com Falsarella; Amorin, (2008), a noção de disciplina na escola sempre foi entendida como "não-movimento" e as crianças educadas e comportadas são aquelas que simplesmente não se move. Ainda segundo esssas autoras, alguns julgam que, para ocorrer a aprendizagem, e preciso que o aluno esteja sempre sentado e quieto. Porém, privilegiar a mente e relegar o corpo pode levar a uma aprendizagem empobrecida (SCARPATO, 2001).

Observamos que a dança ainda passa por um processo de valorização, já que nem sempre consegue o devido espaço comparando-se com os demais conteúdos escolares (PEREIRA, 2007).

\section{Metodologias de ensino de dança na pré-escola}

A dança na educação infantil deve ser vista como uma dinâmica de possibilidades que o professor tem para estimular os movimentos e a capacidade intelectual dos alunos. Segundo Damásio (2000) a dança deve ser abordada através de ações que impliquem o corpo da criança numa globalidade, que vão colocar em jogo a mobilidade da coluna vertebral, pretendendo-se que da globalidade à segmentação, as partes do corpo tornem-se "autônomas", pois a criança aprende primeiro o todo para depois aprender as partes.

Ainda segundo esse autor, as aulas de dança para criança geralmente tem seu eixo pedagógico sustentado na imitação e na repetição de gestos técnicos. Porém alguns autores não concordam com essa percepção, como exemplo de Laban (1990), onde afirma que nesta fase 
inicial a criança deve apenas reagir a estímulos e não imitar, empregando suas próprias ideias e esforços.

Uma das maneiras de estimular a criança a ter movimentos ensaidados e/ou naturais, baseia-se em metodologias que envolvam diversos rítimos musicais. Num país em que pulsam o bumba-meu-boi, o maracatu, o frevo, o samba, o afoxé, a catira, o forró, xote, baião e xaxado, o funk, o rap, o hip-hop, as danças de salão, balés clássicos, torna as aulas de danças dinâmica e interessante.

Para as crianças, as metodologias exploradas pelo professor devem estar relacionadas às cantigas infantis que são bastante utilizadas nas escolas, tais como: se essa rua fosse minha, ciranda cirandinha, capelinha de melão, borboletinha entre outras. Desa forma, os professores ao fazerem os gestos com o corpo, estimulam as crianças a se movimentarem também.

Silva (2001, p.140) propõe uma atividade muito interessante e muito simples que tem como finalidade trabalhar o ritmo com as crianças da seguinte forma: uma ao lado da outra, levantam uma perna podendo começar com a esquerda ou direita e ao levantar tirando a perna do chão ele conta 1 , depois colocam as pernas juntas voltando ao normal e conta 2 isso seguindo um ritmo ditado pela professora. Uma variação dessa atividade seria levar a perna a frente, ora a esquerda ora a direita e contando 1 e 2 como na anterior, a última forma levantando e abaixando, contando 1 e 2, dobrando os joelhos e se erguendo, sempre seguindo um ritmo na voz ao contar os números 1 e 2.

Calfa (2013) também aborda em sua metodologia baseada na corporeidade, em que o estudo das partes do corpo enfocando a sua relação com o todo, proporciona à criança descobrir as suas possibilidades de movimento e de expressividade e a perceber a sua autonomia.

Dessa forma, Trigo, (2014, p. 36) relata que:

\footnotetext{
Numa proposta de caráter interdisciplinar, estabelece em sua metodologia "diálogos poéticos do corpo" com outras linguagens como a literatura, a imagem, o som e o objeto. Abordando a Corporeidade como uma questão, traz também discussões filosóficas a respeito do corpo, da linguagem, da identidade e da memória na Dança. (TRIGO, 2014, p. 36)
}

Para aplicação dessas metodologias no ensino da dança na pré-escola, é fudamental que o professor de dança explore os movimentos naturais de cada criança, seu ritmo próprio, sua expressão. As aulas têm um caráter mais lúdico e descontraído e é introduzida gradativamente, porém respeitando as condições físicas e psíquicas de cada idade, as necessidades globais e as aspirações de cada um. 
Como recursos complementares para implantação dessas metodologias, o professor poderecorrer as diversas formas de tecnologias tais como o som; cds, pen drives previamente gravados com músicas infantis.

\section{Análises de pesquisas de campo - A dança na prática educativa infantil}

Apesar do discurso de que o brasileiro dança, sabe e gosta de dançar - há pouca investigação na área, poucos pesquisadores e pensadores do tema. É importante destacar que atualmente a dança está ganhando um espaço nas pesquisas, pois na década de 80 Patrícia Stokoe (1987) em seu estudo sobre a expressão corporal, percebeu-se uma carência de novas concepções em termos de propostas pedagógicas para esta etapa da Educação.

Em trabalho realizado por Falsarella; Amorim, (2008) avaliando a importancia da dança no desenvolvimento psicomotor de crianças e adolescentes, concluiram que de modo geral, os pais/mães questionados mencionaram que suas filhas obtiveram melhoria em todos os aspectos motores, emocionais, e cognitivos.

Analisando o trabalho de Serafin (2012), que teve como objetivo descrever "A dança, na educação infantil com um efeito pedagógico no espaço escolar”. Esse trabalho contou com a participação dos professores que trabalham com o pré-escolar na Escola Municipal Pedro Eugênio Marcílio, na cidade de Buritis, Rondônia. As metodologias aplicadas foram através de coreografias de música infantis e culturais.

Ao final da pesquisa, foi concluido que $100 \%$ dos professores do pré-escolar trabalham com a música nas suas aulas, além disso, os professores afirmam que com música, é possível desenvolver a capacidade cognitiva e intelectual dos alunos.

Porém, foram encontradas algumas dificuldades para realização das aulas de dança na educação infantil. A pesquisa revelou que todos atribuiram as dificuldades ao espaço físico e material, pois muitas vezes as aulas eram interropindas ou canceladas por tais probelmas.

\section{Considerações Finais}

Com base na análise literária realizada dessa obra, conclui-se que a dança é fundamental para o desenvolvimento corporal e congnitivo das crinaças e essas são dependentes das habilidades dos professores em realizar as atividades de dança como ferramenta educativa. 
Ainda nessa questão, o professor como educador tem a possibilidade de organizar junto com as crianças e seus familiares, bem como membros da comunidade escolar, apresentações que demonstrem a importância da dança como processo educativo. Além disso, é necessário que os professores busquem metodologias de ensino da dança que tenha impacto direto no desenvolvimento congnitivo do aluno.

Destaca-se como metodologias, o uso de músicas de cantigas infantis como: se essa rua fosse minha, ciranda cirandinha, capelinha de melão, borboletinha entre outra, que promovam o estímulo da criança em se movimentar e descobrir suas habilidades motoras.

Porém, cabe aqui a crítica quanto a falta de investimento e incentivo ao professor de dança, pois assim como os relatos de falta de espaço e meterial para as aulas de dança na educação infantil nessa obra, é comum encontrarmos essa condiação de trabalhos, principalmente na rede pública de ensino.

Assim, é necessário fazer uma reflexão sobre a dança dentro do ambiente escolar e a que se pense nas crianças enquanto ser humano, onde necessitam expor suas vontades naturais de correr, pular, brincar e se divertir.

\section{Referências}

CALFA, M. I. S. Cadernos de registro de Monitoria da disciplina Introdução ao Estudo da Corporeidade - Curso de Licenciatura em Dança, Laboratório de Arte-Educação, Departamento de Arte Corporal, Escola de Educação Física e Desportos - UFRJ. Rio de Janeiro, 2013.

DAMÁSIO, C. A dança para crianças. In: PEREIRA, R. e SOTER, S. (orgs.) Lições de Dança 2, Rio de Janeiro: UniverCidade, 2000.

FALSARELLA, A. P., AMORIM, D. B. A importância da dança no desenvolvimento psicomotor de crianças e adolescentes. Revista Conexões, v. 6, p. 306-317, 2008.

FUX, M. Dança, experiência de vida. São Paulo: Summus, 1983.

GARCIA, J. L.; GLITZ, N. B. A influência da dança na qualidade de vida dos idosos. Buenos Aires, $\mathrm{n}^{\circ} 139,2009$.

LAUAR, S. J.; MATTOS, A. M. A dança na escola como elemento lúdico e suas contribuições para aprendizagem, 2014. Disponível em: < http://www.cdof.com.br/danca10.htm>. Acesso em: 24 de set. 2017.

MARBÁ, R. F.; SILVA, G. S.; GUIMARÃES, T. B. Dança na promoção da saúde e melhoria da qualidade de vida. Revista Científica do ITPAC, Araguaína, v.9, n.1, Pub.3, 2016. 
MARQUES, I. A. Linguagem da dança: arte e ensino. São Paulo: Digitexto, 2010.

MARQUES, I A. Ensino de Dança Hoje. São Paulo: Cortez, 1999.

NANI, D. Dança - Educação: Pré-escola à Universidade. Rio de Janeiro: Sprint, 1995.

OLIVEIRA, V. M. de. O que é educação física. São Paulo: Brasiliense, 2001.

SILVA, P. A Canção na Pré Escola. São Paulo: Paulinas, 6 ed, 2001.

STRAZZACAPPA, M.; MORANDI, C. Entre a arte e a docência: a formação do artista da dança. Campinas: Papirus Editora, 2006.

STOKOE, P.; HARF, R. Expressão Corporal na pré- escola. São Paulo: Summus, v. 30, 1987.

TRIGO, C. V. C. A corporeidade na Pré-Escola: pensando uma metodologia para o ensino da Dança. Trabalho de conclusão do curso de Licenciatura em Dança da UFRJ. Rio de Janeiro, 2014.

PEREIRA, M. L. A formação acadêmica do professor de educação física: em questão o conteúdo da dança [dissertação]. Rio Claro (SP): Universidade Estadual Paulista, Instituto de Biociências; 2007.

SCARPATO, Marta Thiago. Dança Educativa: um fato em escolas de São Paulo. Cadernos Cedes, ano XXI, n. 53, abril/2001.

SERAFIM, M. S. Dança, na educação infantil: Efeitos de um Programa de Intervenção Pedagógica. 48 f. Trabalho de Conclusão de Curso II do Curso de Licenciatura em Educação Física do Programa UAB da Universidade de Brasília - Pólo Ariquemes-RO, 2014.

SILVA, J. U. Projeto: Artes na Educação Especial - "O corpo e a mente em ação". 2009. p. 07. Disponível em: <http://lucasdorioverde.apaebrasil.org.br/arquivo.phtml?a=13452>. Acesso em: 24 de set. 2017.

SOUSA, N, C. P .; CARAMASCHI, S.; HUNGER, D. A. C. F. A Dança na Escola: um sério problema a ser resolvido. Motriz, v.16 n.2 p.496-505, 2010.

TREVISAN, P. R. T. C. Influências da dança na Educação das crianças. 2006. Disponível em: <http://www.psicopedagogia.com.br/artigos/artigo.asp?entrID=862. Acesso em: 24 de set. 2017.

WALLON, H. Objetivos e métodos da psicologia. Tradução de Franco de Sousa. Lisboa. Editorial Estampa, 1975.

Como citar este artigo (Formato ABNT):

LIMA, Paula S. de S. A Contribuição da Dança na Pré-Escola. Id on Line Revista Multidisciplinar e de Psicologia, 2017, vol.11, n.38, p. 445-453. ISSN: 1981-1179.

Recebido: 30.10 .2017

Aceito: 01.11.2017 